\title{
Thoracic epidural for modified radical mastectomy in a high-risk patient
}

\author{
Otu E. Etta, Nsese Udeme
}

Department of Anaesthesia, University of Uyo Teaching Hospital, Uyo, Nigeria

Correspondence: Dr Otu E. Etta (otuetta@yahoo.com)

\section{Case presentation}

A 52-year-old woman was scheduled for modified radical mastectomy on account of advanced carcinoma of the right breast. The patient was a known hypertensive and diabetic, diagnosed 3 years prior to presentation and also a known asthmatic, diagnosed at childhood. She was being managed with lisinopril, amlodipine, and Mixtard insulin injection. However, she was not compliant on her medications. Three days before the scheduled surgery, her blood pressure (BP) was $170 / 110 \mathrm{mmHg}$, and fasting blood sugar was 10.8 $\mathrm{mmol} / \mathrm{L}$. Additionally, she suffered an asthmatic attack 2 days prior to surgery. Her regular doses of antihypertensive drugs and insulin(42 IU/day) were increased, while salbutamol inhaler at 2 puffs as required, along with aminophylline and prednisolone tablets were used to manage the mild asthmatic attack.

On the evening prior to surgery her vital signs were as follows: pulse rate (PR) 88/minute, BP 130/70 $\mathrm{mmHg}$, respiratory rate (RR) $20 /$ minute and temperature $36.8^{\circ} \mathrm{C}$. Her chest was clinically clear and other examination findings were normal. Her packed cell volume (PCV) was 36\%. Electrocardiogram (ECG) and chest $x$-ray findings were suggestive of left ventricular hypertrophy. Other investigation results, including electrolyte, urea, and creatinine were within normal limits. Based on the comorbid conditions, she was assigned class to III of the American Society of Anesthesiologists (ASA) classification scheme. She was counselled for thoracic epidural anaesthesia, as general anaesthesia was considered a more risky alternative, and consent for the procedure was obtained.

On the morning of surgery her fasting blood sugar was 8.9 $\mathrm{mmol} / \mathrm{L}$ and $500 \mathrm{~mL}$ of $5 \%$ dextrose water infusion, into which $5 \mathrm{mmol}$ of potassium and $5 \mathrm{IU}$ of soluble insulin were added, was set up to run at $100 \mathrm{~mL} /$ hour. Additionally, the morning doses of her regular antihypertensive medications were given.

In theatre, a multiparameter monitor was attached to the patient, measuring peripheral capillary oxygen saturation and noninvasive BP. Baseline values were as follows: PR 84/ minute, BP 110/70 $\mathrm{mmHg}$, and $\mathrm{SpO}_{2} 96 \%$. In the sitting position, a midline thoracic epidural was performed at the T4/T5 interspinous space using a size 18G Tuohy epidural needle and loss of resistance to air technique. The skin epidural depth was $5 \mathrm{~cm}$, and $4 \mathrm{~cm}$ of the epidural catheter was left in situ in the epidural space in the cephalad direction, and the catheter adhered to the back with adhesive tape. After a test dose of $3 \mathrm{~mL}$ of $1 \%$ lidocaine with adrenaline, a loading dose of $7 \mathrm{~mL}$ of $2 \%$ lidocaine with adrenaline 1:200,000 was given in $4 \mathrm{~mL}$ and $3 \mathrm{~mL}$ aliquots at 5 -minute intervals. The epidural catheter was connected to a syringe pump for continuous infusion of $2 \%$ lidocaine-adrenaline at $4 \mathrm{~mL}$ /hour.

Five minutes later, a sensory block height of T1 to T10 was achieved bilaterally, and the surgery commenced. The breast tissues and tumour were excised en bloc, including fibrofatty tissues of the medial aspect of the right axilla. Oxygen was given via face mask at $4 \mathrm{~L} /$ minute throughout the duration of the surgery, which lasted for 2 hours, 40 minutes. No sedation was used.

The estimated blood loss was $1.2 \mathrm{~L} ; 1$ unit of blood was transfused, and a total of $3 \mathrm{~L}$ of normal saline was infused. The mean random blood sugar (measured hourly) was 12.5 $\mathrm{mmol} / \mathrm{L} ; 6 \mathrm{mmol} / \mathrm{L}$ of soluble insulin was administered once, in addition to the continuous glucose, potassium, insulin infusion. The patient remained haemodynamically stable and comfortable throughout the procedure.

Postoperatively, the patient was admitted to the intensive care unit for observation and pain management, which consisted of continuous infusion of $0.5 \%$ lidocaine-adrenaline at 4 $\mathrm{mL} /$ hour, and intravenous paracetamol at $600 \mathrm{mg}$ 8-hourly for 48 hours to complement analgesia. The patient resumed oral feeding about 6 hours postoperatively. Soluble insulin was converted to Mixtard insulin injection twice daily, oral antihypertensive was commenced on the first postoperative day. The patient was discharged from the ICU and the hospital on the second and sixth postoperative days, respectively.

\section{Discussion}

Mastectomy is traditionally performed under general anaesthesia. This was the first case of mastectomy under thoracic epidural anaesthesia in our centre. In a previous study, Balzarena documented the safety and superiority of thoracic epidural over general anaesthesia in 40 patients scheduled for mastectomy. In that study, thoracic epidural was found to be superior to general anaesthesia in terms of haemodynamic stability, reduced nausea and vomiting, lower analgesic consumption, superior postoperative analgesia, and shorter duration of hospitalisation. ${ }^{1}$ Similar observations have been reported by other researchers. ${ }^{2,3,4}$

The infrequent use of thoracic epidural anaesthesia for oncologic breast surgeries in our environment may be attributed to fear of potential complications of thoracic epidural, which include spinal injury, epidural haemetoma and abscess, as well as postdural puncture headache. However, with experience and due precautions, these complications are extremely rare. ${ }^{45}$

Moreover, the benefits of thoracic epidural anaesthesia makes it a technique of choice in high risk patients. ${ }^{1}$ Previous studies have identified history of hypertension as a risk factor for cardiovascular complications during general anaesthesia. ${ }^{6}$ 
Hypertension has also reported to be more common intraoperatively in patients undergoing surgeries under GA compared to thoracic epidural. ${ }^{1}$ During general anaesthesia, large increases in blood pressure are usually precipitated by laryngoscopy and intubation, surgical stimulation, and extubation. ${ }^{1}$ These airway manipulations are usually avoided in thoracic epidural anaesthesia and hence our patient was haemodynamically stable throughout the procedure.

Surgery in diabetic patients is associated with greater perioperative mortality than surgery in nondiabetic subjects. ${ }^{7,8}$ This is due in part to higher incidences of coronary heart disease, hypertension, renal insufficiency and hyperglycemia among patients with diabetes. ${ }^{8} 9$ The metabolic response to surgery and anaesthesia promotes hyperglycaemia. This is due to the increased secretions of counterregulatory hormones (cathecolamines, cortisol, glucagon and growth hormone) and excessive release of inflammatory cytokines. ${ }^{10}$ The magnitude of the counterregulatory response relates to the severity of surgery, as well as the type of anaesthesia. General anaesthesia has been shown to result in higher blood glucose concentrations compared to local and epidural anaesthesia. ${ }^{8}$ On the other hand, spinal epidural abscess is a rare but potentially life-threatening complication of spinal or epidural anaesthesia. This risk is increased in diabetic patients compared to nondiabetics. ${ }^{11,12}$ However, the risk-benefit assessment of our patient favoured epidural anaesthesia.

Glycaemic control was suboptimal in this patient. This may be attributed to the extensive nature of dissection involved in mastectomy. We used 5\% dextrose water plus $5 \mathrm{IU}$ of insulin and $5 \mathrm{mmol}$ of potassium. Perhaps the addition of $10 \mathrm{IU}$ of insulin would have improved the glycaemic control. Regional anaesthesia, especially epidural where feasible, has been reported to be safer in asthmatic patients compared to general anaesthesia. ${ }^{13}$ Apart from avoiding airway manipulations, which may trigger asthmatic attacks, epidural anaesthesia improves wheezing and ameliorates status asthmaticus. ${ }^{14}$ Although our patient had an asthmatic attack 2 days prior to surgery and was treated, she remained stable throughout the procedure.

Etta and Edubio, ${ }^{13}$ previously reported on thoracic epidural anaesthesia for laparotomy in an asthmatic patient. Their patient developed acute asthmatic attack postoperatively in the general ward, and this was attributed to inadequate analgesia since pentazocine and paracetamol were used as per the surgeon's order for acute pain management. Our patient was admitted to the ICU for continuous epidural analgesia using a syringe pump for at least 48 hours postoperatively. This enabled the patient to receive the full benefit of epidural analgesia, since syringe pumps and nurses trained in epidural analgesia management were not available in the general ward.

\section{Conclusions}

Thoracic epidural anaesthesia and analgesia for mastectomy is feasible, and it offers additional benefits in high-risk patients.

\section{Acknowledgements}

We acknowledge Professor Sylvia G. Akpan for her contributions to this work.

\section{Competing interests}

The authors declare that they have no conflicts of interest.

\section{References}

1. Balzarena SD. Comparative study between thoracic epidural block and general anaesthessia for oncologic mastectomy. Rev Bras Anestesiol 2008, 58(6): 561-8

2. Lynch EP, Welch KJ, Carabuena JM, Eberlein TJ. Thoracic epidural anaesthesia improves outcome after breast surgery. Ann Surg 1995; 222(5): 663-669.

3. Asegaonkar BN, Zine SR, Takalkar UV, Kulkarni U. Asegaonkar SB, kodlikeri P. Thoracic epidural anaesthesia for modified radical mastectomy in carcinoma of breast patient with chronic obstructive pulmonary disease: A case report. International Journal of case reports and images 2013;4(5): 546-550

4. Etta OE, Umeh K, Akpan SG. Thoracic epidural anaesthesia for major abdominal surgeries: experience in private hospital setting in Uyo, SouthSouth Nigeria. SAJAA 2016; 22(3): 86-88.

5. Tanaka K, Watanabe R, Harada T, Dan K. Extensive application of epidural anaesthesia and analgesic in a university hospital: Incidence of complications related to technique. Reg Anesth 1993; 18(1): 34-38

6. Howel SJ, Sear YM, Yeates D, Goldacre M, Sear JW, et al. Risk factors for cardiovascular death after elective surgery under general anaesthesia. Br J Anaesth 1998; 80: 14-19

7. Vishwanath RH. Thoracic Epidural anaesthesia for modified radical mastectomy in type 2 Diabetes mellitus patient. Journal of medical and dental sciences 2014; 3(70): 15002-15006

8. Rehman HU, Mohammed K. Perioperative management of diabetic patients. Curr Surg 2003; 60: 607-611

9. Umpierrez GE, Isaacs SD, Bazargan N, et al. Hyperglycemia: an independent marker of in-hospital mortality in patients with undiagnosed diabetes. J Clin Endocrinol Metab 2002; 87: 978-982

10. Mizock BA. Blood glucose management during critical illness. Rev Endocr Metab Disorder 2003; 4: 187-194

11. Tang HJ, Lin HJ, Liu YC, Li CM. Spinal epidural abscess- experience with 46 patientsand evaluation of prognostic factorsJ Infect 2002; 45(2): 76-81.

12. Reihsaus G, Waldbaur H, Seeling W. Spinal epidural abscess: a metaanalysis of 915 patients. Neurosurg Rev 2000; 23(4): 175-204.

13. Etta OE, Edubio MN. Awake thoracic epidural anaesthesia for laparotomy: A safer alternative to general anaesthesia in asthmatic patients. Ibom Medical journal 2014; 7(2): 6-10.

14. Shono S, Higa K, Katori K, Nitahara K, Hamada T, et al. Med Bull Fakuoka Univ 2008; 35: 51-156. 